\title{
Frequency of myopia in adults in Mexico City: results of a visual health campaign
}

\section{Frecuencia de miopía en adultos de la Ciudad de México: resultados de una campaña de salud visual}

\author{
Roberto Milán-Castillo*, Francisca Domínguez-Dueñas, and Aleyda Molina-Lespron \\ Ophthalmology Service, Instituto Nacional de Rehabilitación Luis Guillermo Ibarra Ibarra, Mexico City, Mexico
}

\begin{abstract}
Purpose: To estimate the frequency of myopia in an adult population in Mexico City. Methods: Retrospective, cross-sectional and descriptive study. The spherical equivalent of the right eye was calculated from the refraction without cycloplegia obtained with an auto kerato-refractometer in patients examined during an ophthalmic health campaign carried out at the Instituto Nacional de Rehabilitación "Luis Guillermo Ibarra Ibarra" from January to March 2018. Results: We found a frequency of myopia of $45.21 \%$ with a cut-off value of $\leq-0.5$ diopters of spherical equivalent in the 449 participants. Of these, $39.43 \%$ had mild myopia > -6.00 diopters, and 5.79\% had high myopia $\leq-6.00$ diopters of spherical equivalent. On the other hand, only 4 of the 449 examined patients had clinical signs of pathological myopia, making up $0.8 \%$ of the total sample. Of the remaining participants, $28.73 \%$ were classified as emmetropic and $26.05 \%$ as hyperopic, with a spherical equivalent $\geq 0.50$ diopters. Conclusions: The frequency of myopia observed in our study is high and similar to that informed in previous reports in Mexican children and young adults, just as in some nations in Asia where myopia is a public health problem.
\end{abstract}

Keywords: Myopia. Refractive error. Frequency. Mexico City. Adults.

\section{Resumen}

Objetivo: Estimar la frecuencia de miopía en una población de adultos en la Ciudad de México. Método: Fue un estudio retrospectivo, transversal y descriptivo. Se calcularon los datos del equivalente esférico del ojo derecho de los pacientes examinados a partir de la refracción sin cicloplejia, determinada por medio de un autoqueratorrefractómetro durante la campaña de salud ocular que se llevó a cabo en el Instituto Nacional de Rehabilitación Luis Guillermo Ibarra Ibarra de enero a marzo de 2018. Resultados: La frecuencia de miopía encontrada en los 449 sujetos analizados fue del $45.21 \%$, tomando como punto de corte un equivalente esférico $\leq-0.50$ dioptrías; de ellos, el $39.43 \%$ tuvieron miopía leve (> -6.00 dioptrías) y el $5.79 \%$ miopía alta ( $\leq-6.00$ dioptrías de equivalente esférico). Por otra parte, solo 4 de los 449 pacientes examinados presentaron datos clínicos de miopía patológica, conformando el $0.8 \%$ de la muestra total. De los participantes restantes el $28.73 \%$ fueron clasificados como emétropes y el $26.05 \%$ como hipermétropes con un equivalente esférico $\geq 0.50$ dioptrías. Conclusiones: La frecuencia de miopía encontrada en nuestro estudio es alta y se asemeja a la de reportes previos en población mexicana infantil y de adultos jóvenes, así como a la de algunas naciones asiáticas donde la miopía es un problema de salud pública.

Palabras clave: Miopía. Error refractivo. Frecuencia. Ciudad de México. Adultos.

Correspondence:

*Roberto Milán-Castillo

Avda. Forestal 127, Dpto. 24a, Col. Huipulco, Date of reception: 19-11-2020 Del. Tlalpan C.P. 14370, Mexico City, Mexico

E-mail: robbiemilan90@gmail.com
Date of acceptance: 07-06-2021

DOI: 10.24875/RMOE.M21000181 2604-1731/@ 2021 Sociedad Mexicana de Oftalmología. Published by Permanyer. This is an open access article under the CC BY-NC-ND license (http://creativecommons.org/licenses/by-nc-nd/4.0/).

Available online: 01-09-2021 Rev Mex Oftalmol (Eng). 2021;95(5):197-202

www.rmo.com.mx 


\section{Introduction}

Myopia is defined as a refractive error in which light rays parallel to the optic axis that enter the eye are focused in front of the retina when ocular accommodation is relaxed ${ }^{1}$. Myopia is a major risk factor for several eye disorders such as nuclear cataract ${ }^{2}$, glaucoma ${ }^{3-5}$, retinal detachment ${ }^{6}$, choroidal neovascularization and myopic macular degeneration?

Uncorrected refractive errors are considered the world's leading cause of visual impairment ${ }^{8}$. In 2010 it was estimated that myopia affected 1893 million people in the world and, if current prevalence rates do not change, projections show that it will affect 4949 million people (representing $49.8 \%$ of the world population) by $2050^{9}$.

The prevalence of myopia varies significantly between racial groups. According to published studies, the highest prevalence is observed in East Asia, where myopia figures of $96.5 \%{ }^{10}$ and $83.3 \%{ }^{11}$ were reported in 19-year-old South Korean individuals residing in urban and rural areas, respectively, while in Taiwan a prevalence of $86.1 \%$ was estimated in young adults between 18 and 24 years old ${ }^{12}$, and in China, it was $84.6 \%$ in adolescents aged 17 years $^{13}$.

In Mexico, the studies carried out have mainly evaluated the prevalence of myopia in children and adolescents; only one also included the adult population. In 2003, a prevalence of myopia of $44 \%$ was reported in children between 12 and 13 years old in Monterrey, Nuevo León ${ }^{14}$. In a suburban area of Estado de Mexico, children between 6 and 15 years old were evaluated, finding a prevalence of myopia of $33 \%{ }^{15}$, while another study that evaluated children between 6 and 12 years old in a rural area of the same State found a prevalence of myopia of $9.7 \%{ }^{16}$. Finally, in 2017, a study was published on the proportion of refractive errors in 14 entities in Mexico in individuals aged 6-90 years, finding $24.8 \%$ of subjects with myopia ${ }^{17}$.

Myopia is a relevant public health issue with important socioeconomic implications not only in Mexico, but throughout the world, due to its complications and other serious disorders associated with it ${ }^{8}$.

Until now, there are few epidemiological data reported in the literature about myopia in Mexico; therefore, the objective of the study was to determine the frequency of this refractive error in an adult population of Mexico City.

\section{Methods}

\section{Study design, population, and sampling}

Through a cross-sectional and descriptive study, we obtained clinical data from a population of Mexican individuals aged $>18$ years of age, who participated in an eye health campaign that was carried out at the Instituto Nacional de Rehabilitación Luis Guillermo Ibarra Ibarra from January to March 2018.

\section{Inclusion, exclusion, and elimination criteria}

We included subjects over 18 years of age, of Mexican nationality, of any sex, who participated in the eye health campaign carried out at the Instituto Nacional de Rehabilitación Luis Guillermo Ibarra Ibarra from January to March 2018. Individuals who had undergone refractive, cataract, or vitreoretinal surgery were excluded. Patients which had incomplete records, who did not complete the diagnostic studies, and those with ocular disorders that did not allow measuring refraction by auto kerato-refractometer were eliminated.

\section{Study procedures in the eye health campaign}

We collected data from participants for 3 months. The team consisted of seven residents and one faculty physician from the ophthalmology department. Informed consent was obtained to participate in the study and the following procedures were carried out: medical history including identification card (name, age, sex and place of birth), specific questions about the ocular history and symptoms, visual acuity measurement using the Snellen chart, refraction using the KR-800 auto kerato-refractometer (Topcon, Tokyo, Japan) prior to pharmacological mydriasis, biomicroscopy exam with a B900 slit lamp (Haag-Streit AG, Köniz, Switzerland), and fundus examination under pharmacological mydriasis with a 78 or $90 \mathrm{D}$ aerial lens to evaluate the retina, macula, and optic disc.

\section{Classification of the refractive state and definition of pathological myopia}

We used data only from the right eye to classify patients according to their refractive error, following the classification standards proposed by the International Myopia Institute for clinical and epidemiological studies ${ }^{18}$. Myopia was considered as a spherical equivalent (SE) $\leq-0.5$ diopters (D), mild myopia as a SE $\leq-0.5$ and $>-6.00 \mathrm{D}$, high myopia as a $\mathrm{SE} \leq-6.00 \mathrm{D}$, emmetropia as a SE $>-0.5$ and $<+0.5 \mathrm{D}$, and hyperopia as a SE $\geq+0.5$ D. Similarly, the International Myopia Institute proposes the term "pathological myopia" to 
define an excessive axial elongation associated with myopia that leads to structural changes of the posterior segment of the eye (including myopia-associated posterior staphyloma, myopic maculopathy and optic neuropathy) that can induce a decrease of best-corrected visual acuity.

The protocol adhered to the Declaration of Helsinki and was approved by the Ethics Committee of the Instituto Nacional de Rehabilitación Luis Guillermo Ibarra Ibarra. All patients agreed and signed an informed consent before performing any study procedures.

\section{Results}

We included 449 right eyes of 449 Mexican patients, 304 female $(67.70 \%)$ and 145 male $(32.30 \%)$. The minimum age was 21 years, and the maximum was 89 years, with a mean age of 55.3 years. Demographic characteristics are summarized in Table 1.

Regarding the frequency of myopia in the 449 patients, 203 (45.21\%) were within the myopia range (SE: $\leq-0.5 \mathrm{D})$; of the remaining subjects, $129(28.73 \%)$ were considered emmetropic (SE: > $-0.5 \mathrm{D}$ and $<+0.5 \mathrm{D}$ ) and $117(26.05 \%)$ were included within the hyperopia group (Table 2). The distribution of refractive errors in the total population is shown in Figure 1.

Of the 203 patients with myopia $(45.21 \%)$, $177(39.42 \%)$ had a SE $\leq-0.5 \mathrm{D}$, but $>-6.00 \mathrm{D}$, categorizing them as mild myopia; the remaining 26 (5.79\%) patients had a SE $\leq-6.00 \mathrm{D}$, for which they were classified within the group of patients with high myopia (Table 2).

The percentages of myopia in the population were also calculated considering more negative or myopic SE cut-off points, obtaining $38.97 \%$ with a SE $\leq-0.75$ and $34.07 \%$ with a SE $\leq-1.00 \mathrm{D}$.

Regarding pathological myopia, only $4(0.8 \%)$ of the 449 individuals showed clinical data of this disorder.

\section{Discussion}

Studies about the frequency and prevalence of myopia in Mexico are scarce and, based on the literature, this is the first study of the frequency of myopia in a Mexican population carried out specifically in adults (Table 3). The frequency of $45.21 \%$ estimated in our study is comparable to the proportion of $43.4 \%$ found by Gómez-Salazar, et al. ${ }^{17}$ in the group of 20-29 years old; however, it is much higher than the $19.7 \%, 10.7 \%$, and $8.9 \%$ reported by the same authors in the 40-49, 50-59, and 69-year-old
Table 1. Clinical and demographic characteristics of the participants

\begin{tabular}{l|c|}
\hline Characteristics & \\
\hline Number of eyes (patients) & $449(449)$ \\
\hline Age (years) & \\
Mean \pm SD & $55.3 \pm 11.5$ \\
Range & $21-89$ \\
\hline Sex, $\mathrm{n}(\%)$ & \\
Female & $304(67.71)$ \\
Male & $26(32.29)$ \\
\hline Origin, $\mathrm{n}(\%)$ & \\
Mexico City & $348(77.51)$ \\
Estado de México & $16(3.56)$ \\
Oaxaca & $11(2.45)$ \\
Veracruz & $11(2.45)$ \\
Michoacan & $10(2.23)$ \\
Other & $53(11.80)$ \\
\hline Systemic diseases, $\mathrm{n}(\%)$ & \\
Arterial hypertension & $106(23.61)$ \\
Diabetes mellitus & $82(18.26)$ \\
Other & $112(24.94)$ \\
\hline
\end{tabular}

SD: standard deviation.

Table 2. Classification of refractive errors

\begin{tabular}{|l|c|}
\hline Refractive error & $n(\%)$ \\
\hline Myopia & $203(45.21)$ \\
\hline Mild myopia & $177(39.42)$ \\
\hline High myopia & $26(5.79)$ \\
\hline Emmetropia & $129(28.73)$ \\
\hline Hyperopia & $117(26.05)$ \\
\hline Total & $449(100)$ \\
\hline
\end{tabular}

groups, respectively, the age range of the majority of the participants in our campaign. However, it should be noted that these authors designated as myopia a SE $\leq-0.75 \mathrm{D}$. Our data are also similar to the $44 \%$ found by Villarreal, et al. ${ }^{16}$ in 2003 in a pediatric population under cycloplegia and taking as a cut-off point a SE $\leq-0.5 \mathrm{D}$.

Our figures are lower compared to other analyses in the adult Latino population, such as the MIOPUR (Determination of the prevalence of myopia and its association with environmental influences in Colombian urban and rural populations), which reported a prevalence of $15.7 \%$ and $9.2 \%$ in urban and rural populations, respectively ${ }^{19}$. Similarly, the Los Angeles Latino Eye Study found a prevalence of myopia of $16.8 \%$ in adults over 40 years of age from a Latino population 
Rev Mex Oftalmol (Eng). 2021;95(5)

Table 3. Studies on the frequency or prevalence of myopia in Mexico

\begin{tabular}{|c|c|c|c|c|c|c|c|c|}
\hline Study & $\begin{array}{l}\text { Year of } \\
\text { study }\end{array}$ & City & Zone & n & $\begin{array}{c}\text { Age } \\
\text { (years) }\end{array}$ & Cycloplegia & $\begin{array}{l}\text { Spherical } \\
\text { equivalent }\end{array}$ & $\begin{array}{c}\text { Patients } \\
\text { with } \\
\text { myopia }\end{array}$ \\
\hline Villarreal, et al. ${ }^{14}$ & 1999 & Monterrey, N.L. & Urban & 1035 & $12-13$ & Yes & $\leq-0.50 \mathrm{D}$ & $44 \% *$ \\
\hline $\begin{array}{l}\text { Rodríguez-Ábrego, } \\
\text { et al. }{ }^{15}\end{array}$ & 2001 & $\begin{array}{l}\text { Nezahualcóyotl, } \\
\text { Mex. }\end{array}$ & Suburban & 1136 & $6-15$ & No & $\leq-0.50 \mathrm{D}$ & $33 \% *$ \\
\hline $\begin{array}{l}\text { Gómez-Salazar, } \\
\text { et al. }{ }^{17}\end{array}$ & 2014-2015 & Various & Several & 676.856 & $6-90$ & No & $<-0.50 \mathrm{D}$ & $24.8 \%^{\dagger}$ \\
\hline $\begin{array}{l}\text { García-Liévanos, } \\
\text { et al. }{ }^{16}\end{array}$ & $2016^{\ddagger}$ & $\begin{array}{l}\text { Temascalapa, } \\
\text { Mex. }\end{array}$ & Rural & 317 & $6-12$ & No & $\leq-0.50 \mathrm{D}$ & $9.7 \% *$ \\
\hline Milán, et al. & 2018 & $\begin{array}{l}\text { Mexico City, } \\
\text { Mexico. }\end{array}$ & Urban & 449 & $21-89$ & No & $\leq-0.50 \mathrm{D}$ & $45.21 \%^{\dagger}$ \\
\hline
\end{tabular}

*Prevalence studies.

'Study of frequency or proportion.

¥Year of publication, the year in which the data was obtained is not mentioned in the article.

D: diopters.

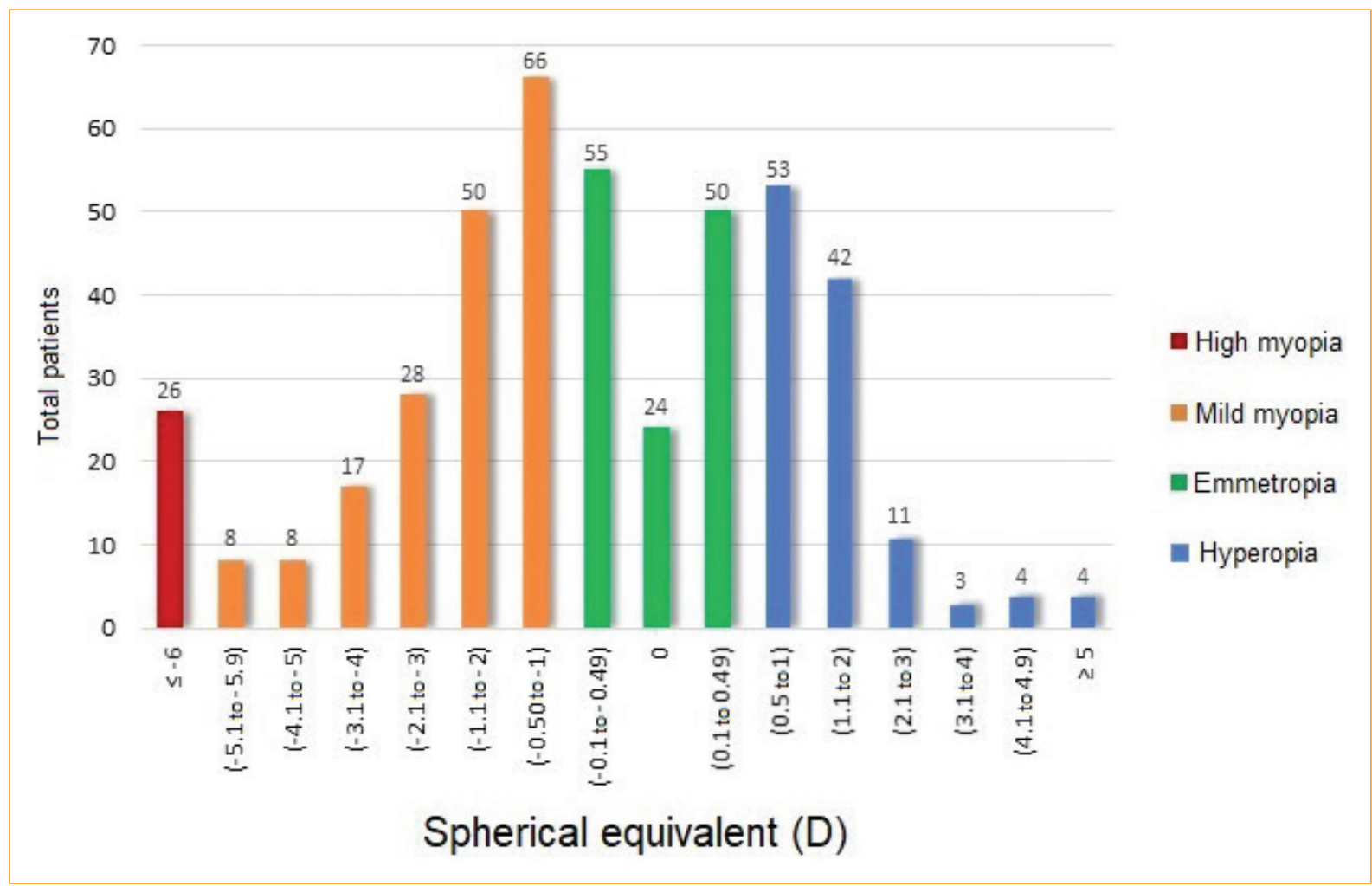

Figure 1. Distribution of refractive errors in the total population $(n=449)$ according to the spherical equivalent. D: diopters.

residing in the United States of America; however, in this publication, they considered a SE $\leq-1.00 \mathrm{D}$ to classify the population as myopic ${ }^{20}$.

Compared with studies conducted in Asia, our percentages were slightly lower than those estimated by the Nagahama Study in Japan, with a prevalence of myopia in adults aged 34 to 80 years of $49.97 \%{ }^{21}$, while in adults aged 20-40 years in Saudi Arabia, there was a reported prevalence of $48.7 \%{ }^{22}$, both with a SE $\leq-0.50$ $\mathrm{D}$ as the definition of myopia. 
In Europe, there was an estimation of an overall prevalence of $30.6 \%$ in adults aged 25 to 89 years according to a meta-analysis that included 15 studies conducted in various countries ${ }^{23}$.

In our study, when we made additional estimates of the total frequency by adjusting the SE, we obtained frequencies that can also be considered high; for example, with a SE cut-off point $\leq-0.75 \mathrm{D}$, we obtained a figure of $38.97 \%$, and with a $S E \leq-1.00 \mathrm{D}$ the estimation was $34.07 \%$. These adjustments allow compensating for potential biases due to not having performed cycloplegic refraction. Fotouhi, et al. ${ }^{24}$ point out that, in general, the sensitivity in estimating the refractive error with the autorefractometer without cycloplegia for the diagnosis of myopia is $99 \%$, but specificity is $80.4 \%$; this is the opposite of what happens with hyperopia, for which sensitivity is only $47.9 \%$, but specificity is $99.4 \%$. It is also mentioned that, with this method and without cycloplegia, myopia is overestimated at any age, and hyperopia is underestimated, although this overestimation is greater in the groups of 21-30 years and 31-40 years of age.

The SE cut-off points chosen for the classification of refractive errors in our study are based on the figures used by most of the global studies on the prevalence of myopia, highlighting that standardization in definitions and cut-off points are essential to facilitate an evidence-based approach of the evaluation and management of myopia, although they also point out that in those studies in which cycloplegics are not used and a younger population is analyzed, more myopic thresholds should be considered ${ }^{18}$.

Regarding the high myopia figures obtained, with a total of 26 patients that resulted in $5.79 \%$ of all patients, they are still slightly lower than those reported by the Nagahama Study, with a prevalence of almost $7.89 \%$ using a SE $\leq-6.00 \mathrm{D}^{21}$.

Finally, the $0.8 \%$ percentage of pathological myopia was lower compared to that published in population studies, such as the Beijing Eye Study ${ }^{25}$ in China and the Blue Mountains Study ${ }^{26}$ in Australia, with a prevalence of $3.1 \%$ and $1.2 \%$, respectively.

As mentioned earlier, one of the limitations of the study was not having performed cycloplegic refraction, although only a small fraction of the evaluated individuals were under 40 years of age. Likewise, due to the higher number of participants between 40 and 70 years of age, we were unable to evaluate the trend reported in several publications of greater myopia in young adults, followed by a reduction in myopia in older ages and finally a new rebound around the age of $70^{17,19,23}$. On the other hand, many of the adults who attended the visual health campaign to undergo the free comprehensive ocular examination, already had previous contact with ophthalmologists or optometrists, a circumstance that could have generated a greater interest in having an examination compared to the population that has never required ocular care or a correction for refraction, perhaps overestimating the data when extrapolating to a larger population.

\section{Conclusions}

The frequency of myopia observed in our study is much higher than the prevalence reported in the Latino population of other countries; however, it is similar to that of other publications on Mexican children and young adults, as well as that of some Asian nations where myopia is a public health problem. In accordance with this and with the trend observed in recent years, in which myopia is expected to continue to increase, we consider it convenient that this issue be addressed in Mexico with greater attention, in order to be able to intervene in a timely manner in the appearance or progression of this disease that is very easy to diagnose, but with potentially devastating visual repercussions.

\section{Funding}

The authors received no funding for this work.

\section{Conflicts of interest}

The authors declare no conflicts of interest.

\section{Ethical disclosures}

Protection of human and animal subjects. The authors declare that no experiments were performed on humans or animals for this study.

Confidentiality of data. The authors declare that they have followed the protocols of their work center on the publication of patient data.

Right to privacy and informed consent. The authors have obtained the written informed consent of the patients or subjects mentioned in the article. The corresponding author is in possession of this document.

\section{References}

1. Németh J, Tapasztó B, Aclimandos WA, Kestelyn $P$, Jonas JB, de FAber JTHN, et al. Update and guidance on management of myopia. European Society of Ophthalmology in cooperation with International Myopia Institute. Eur J Ophthalmol. 2021 Mar 5;1120672121998960. doi: $10.1177 / 1120672121998960$. Online ahead of print. 
2. Pan CW, Cheng CY, Saw SM, Wang JJ, Wong TY. Myopia and age-related cataract: a systematic review and meta-analysis. Am J Ophthalmol. 2013;156:1021-33.

3. Mitchell P, Hourihan F, Sandbach J, Wang J. The relationship between glaucoma and myopia. The Blue Mountains Eye Study. Ophthalmol. 1999;106:2010-15.

4. Qiu M, Wang SY, Singh K, Lin SC. Association between myopia and glaucoma in the United States Population. Invest Ophthalmol Vis Sci. 2013;54:830-5

5. Marcus MW, de Vries MM, Junoy Montolio FG, Jansonius NM. Myopia as a risk factor for open-angle glaucoma: a systematic review and meta-analysis. Ophthalmol. 2011;118:1989-94.

6. Han X, Ong JS, An J, Craig JE, Gharahkhani P, Hewitt AW, et al. Association of myopia and intraocular pressure with retinal detachment in European descent participants of the UK Biobank Cohort: a Mendelian randomization study. JAMA Ophthalmol. 2020;138:671-8.

7. Haarman AEG, Enthoven CA, Tideman JWL, Tedja MS, Verhoeven VJM, Klaver CCW. The complications of myopia: A review and meta-analysis. Invest Opthalmol Vis Sci. 2020;61:49.

8. Bourne RRA, Stevens GA, White RA, Smith JL, Flaxman SR, Price H et al. Causes of vision loss worldwide, 1990-2010: a systematic analysis. Lancet Global Health. 2013;1:e339-49.

9. Holden BA, Fricke TR, Wilson DA, Jong M, Naidoo KS, Sankaridurg P, et al. Global prevalence of myopia and high myopia and temporal trends from 2000 through 2050. Ophthalmol. 2016;123:1036-42.

10. Jung SK, Lee JH, Kakizaki H, Jee D. Prevalence of myopia and its association with body stature and educational level in 19-year-old male conscripts in Seoul, South Korea. Invest Ophthalmol Vis Sci. 2012:53:5579-83.

11. Lee JH, Jee D, Kwon JW, Lee WK. Prevalence and risk factors for myopia in a rural Korean population. Invest Ophthalmol Vis Sci. 2013;54:5466-71.

12. Lee YY, Lo CT, Sheu SJ, Lin JL. What factors are associated with myopia in young adults? A survey study in Taiwan Military Conscripts. Invest Ophthalmol Vis Sci. 2013;54:1026-33

13. Wu JF, Bi HS, Wang SM, Hu YY, Wu H, Sun W, et al. Refractive error, visual acuity and causes of vision loss in children in Shandong, China: the Shandong Children Eye Study. PLoS One. 2013;8:e82763.

14. Villarreal GM, Ohlsson J, Cavazos H, Mohamed JH. Prevalence of myopia among 12-to 13-year-old schoolchildren in Northern Mexico. Optom Vis Sci. 2003;80:369-73.
15. Rodríguez-Ábrego G, Sotelo-Dueñas HM. Prevalencia de miopía en escolares de una zona suburbana. Rev Med Inst Mex Seguro Soc. 2009; 47:39-44.

16. García-Liévanos O, Sánchez-González L Espinosa-Cruz N Hernández-Flores LA, Salmerón-Leal L, Torres-Rodríguez HD. Myopia in schoolchildren in a rural community in the State of Mexico, Mexico. Clin Optometry (Auckl). 2016;8:53-6.

17. Gomez-Salazar F, Campos-Romero A, Gomez-Campaña $H$, Cruz-Zamudio C, Chaidez-Felix M, Leon-Sicairos N, et al. Refractive errors among children, adolescents and adults attending eye clinics in Mexico. Int J Ophthalmol. 2017;10:796-802.

18. Flitcroft $\mathrm{DI}, \mathrm{He} \mathrm{M}$, Jonas JB, Jong M, Naidoo K, Ohno-Matsui K, et al. IMI - Defining and classifying myopia: a proposed set of standards for clinical and epidemiologic studies. Invest Ophthalmol Vis Sci. 2019; 60:M20-30.

19. Galvis V, Tello A, Otero J, Serrano AA, Gómez LM, Camacho PA, et al. Prevalence of refractive errors in Colombia: MIOPUR study. $\mathrm{Br} \mathrm{J}$ Ophthalmol. 2018;102:1320-23.

20. Tarczy-Hornoch K, Ying-Lai M, Varma R, Paz SH, Abbott LV, Azen SP, et al. Myopic refractive error in adult Latinos: the Los Angeles Latino Eye Study. Invest Ophthalmol Vis Sci. 2006;47:1845-52.

21. Nakao SY, Miyake M, Hosoda Y, Nakano E, Mori Y, Takahashi A, et al. Myopia prevalence and ocular biometry features in a general Japanese population: the Nagahama Study. Ophthalmol. 2021;128:522-31.

22. Almudhaiyan $T$, Alhamzah $A$, AlShareef $M$, Alrasheed $A$, Jaffar $R$, Alluhidan A, et al. The prevalence of refractive errors among Saudi adults in Riyadh, Saudi Arabia. Saudi J Ophthalmol. 2020;34:30-4.

23. Williams KM, Verhoeven VJM, Cumberland P, Bertelsen G, Wolfram C, Buitendijk GH, et al. Prevalence of refractive error in Europe: the European Eye Epidemiology (E3) Consortium. Eur J Epidemiol. 2015; 30:305-15.

24. Fotouhi A, Morgan IG, Iribarren R, Khabazkhoob M, Hashemi H. Validity of noncycloplegic refraction in the assessment of refractive errors: the Tehran Eye Study. Acta Ophthalmol. 2012;90:380-6.

25. Liu HH, Xu L, Wang YX, You QS, Jonas JB. Prevalence and progression of myopic retinopathy in Chinese adults: the Beijing Eye Study. Ophthalmol. 2010;117:1763-68.

26. Vongphanit J, Mitchell $\mathrm{P}$, Wang JJ. Prevalence and progression of myopic retinopathy in an older population. Ophthalmol. 2002;109:704-11. 